\title{
RETRACTED ARTICLE: MAVS protects cells from apoptosis by negatively regulating VDAC1
}

\author{
Yang Xu $\cdot$ Hui Zhong $\cdot$ Wei Shi
}

Received: 1 July 2010/ Accepted: 15 November 2010/Published online: 26 November 2010

(C) Springer Science+Business Media, LLC. 2010

This article is being retracted due to unauthorized use and inclusion of data, in which the author presented data as if it were his own and without proper acknowledgement.

Y. Xu · W. Shi $(\bowtie)$

Key Laboratory for Molecular Enzymology and Engineering, Jilin University, 2519 Jie-Fang Road, 130021 Changchun, China e-mail: zgdlxy@hotmail.com

H. Zhong

Institute of Biotechnology, 100850 Beijing, China 